\title{
Equity, Inclusion and Ethics: Adapting a Mentoring Curriculum to Develop an Ethics Workshop for Engineering Students
}

\section{Dr. Katy Luchini-Colbry, Michigan State University}

Katy Luchini-Colbry is the Assistant Dean for Graduate Student Services at the College of Engineering at Michigan State University, where she completed degrees in political theory and computer science. A recipient of a NSF Graduate Research Fellowship, she earned Ph.D. and M.S.E. in computer science and engineering from the University of Michigan. She has published more than two dozen peer-reviewed works related to her interests in educational technology and enhancing undergraduate education through hands-on learning. Luchini-Colbry is also the Director of the Engineering Futures Program of Tau Beta $\mathrm{Pi}$, the Engineering Honor Society, which provides interactive seminars on interpersonal communications and problem solving skills for engineering students across the U.S.

\section{Dr. Melissa McDaniels, Michigan State University}

Melissa McDaniels is Senior Advisor to the Dean for Research Mentoring at the Graduate School and Postdoc Office at Michigan State University where she has been working to support graduate students and postdocs at Michigan State as they develop their capacities as postsecondary instructors and mentors. She is also an Investigator with and part of the leadership team of the Center for the Improvement of Mentored Experiences in Research at the University of Wisconsin, Madison. In her role as CIMER Investigator, she is leading a project as a part of the APS's NSF INCLUDES Inclusive Graduate Education Network (IGEN). From 2014-2019 she also served as Co-Director of the NIH-supported National Research Mentoring Network's Master Facilitator Initiative. From 2008-2012, McDaniels served as Director of Michigan State University's NSF ADVANCE Grant where she spearheaded the institution's efforts to diversify the faculty in Science, Technology, Engineering, and Mathematics (STEM) fields. In this role she was responsible for the development and implementation of MSU's new faculty mentoring policy. Prior to working at MSU, she held full time positions at Northeastern University, Boston College, and National Geographic Society. McDaniels has over twenty years of experience in graduate student and faculty development, undergraduate and graduate teaching and learning and organizational change. She has had the pleasure of doing research and consulting domestically and internationally.. McDaniels holds degrees from Michigan State University (Ph.D.), Boston College (M.A.), and University of Michigan (B.A.). 


\title{
Equity, Inclusion and Ethics: Adapting a Mentoring Curriculum to Develop an Ethics Workshop for Engineering Students
}

\begin{abstract}
Fifteen years ago, a team of scholars from the University of Wisconsin-Madison created the "Entering Mentoring" curriculum targeting doctoral students in the STEM fields. Since that time, with funding from the National Institutes of Health (NIH), the National Science Foundation (NSF), and other agencies, this curriculum has been adapted for numerous disciplines and career stages and implemented nationwide through both the National Research Mentoring Network (www.nrmnet.net) and the Center for the Improvement of Mentored Experiences in Research (www.cimerproject.org). The initiatives associated with NRMN and CIMER now encompass multi-day training programs, hundreds of case studies, and several published guides for facilitators.
\end{abstract}

In 2017, an NRMN-trained "Master Facilitator" adapted (with permission) portions of curricula that focused on equity, inclusion and ethics. The result was a 3-4 hour interactive workshop for engineering students that: (1) introduces issues in equity, inclusion and ethics as they apply to engineering; (2) models approaches for establishing safe and inclusive learning spaces; and (3) engages participants in case studies and active learning experiences. As part of the workshop, participants examine the code of ethics of the National Society of Professional Engineers (or an appropriate ethical code from their area of engineering specialization). This paper describes the development of this workshop, including early pilot testing and training of facilitators from Tau Beta Pi, the Engineering Honor Society, by colleagues from the University of WisconsinMadison. The workshop was revised based on these early experiences, and the final version was offered 20 times to 326 participants during 2018-19. We discuss results from surveys of these participants; share lessons learned; and offer recommendations for those interested in adopting (or adapting) this open-source curriculum.

\section{Introduction and History of Engineering Futures}

Since the 1980s, Tau Beta Pi (the Engineering Honor Society) has offered interactive professional skills training seminars for college students through the "Engineering Futures" program. Seminars are facilitated by a national network of volunteers using curriculum materials originally donated by Dr. Kerry Patterson, who is now well-known as an author of "Crucial Conversations" [1]. In its first three decades, the Engineering Futures (EF) program grew from a handful of officer training seminars for leaders of campus chapters of Tau Beta Pi into a robust catalog of seminars on communications, teamwork, problem solving, and presentation skills [2]. EF was recognized by ASEE, the American Society for Engineering Education, with the 2007 Excellence in Engineering Education Collaboration Award. By the early 2000s, EF was serving several thousand student participants annually in training sessions hosted on college campuses throughout the United States.

The original EF curriculum materials were donated to Tau Beta Pi with the understanding that they would be used only to train students. This curriculum included paper facilitator manuals, 
flipchart activities and VCR tapes, and these materials were adapted over the decades to reflect changes in classrooms, technology, students and schedules. Some of these adaptations worked better than others, and over time some of the learning objectives and facilitator training materials originally provided by Kerry Patterson were lost. A new module, Effective Presentation Skills, was developed by volunteer facilitators in the mid-2000s and was widely available for all participants (including non-students) by 2010 . This addition was very popular and led to calls for additional, updated training materials that would be accessible to broader audiences of engineers, from students through working professionals and retirees.

The volunteer Director of Engineering Futures (DEF), who is part of the engineering faculty at Michigan State University, led efforts to develop both short- and long-term goals to revitalize the EF program. In the short term, the DEF developed collaborations with other training organizations and explored the availability of open-source training resources that might be integrated into the EF program catalog. This paper describes the outcome of one of these collaborations, with the National Research Mentor Network (NRMN) and the Center for the Improvement of Mentored Experiences in Research (CIMER).

\section{Building Collaborations for Professional Skills Training}

In 2017, the DEF participated in training offered by the Big Ten Academic Alliance to become certified as a facilitator for "Entering Mentoring," a professional skills training program that seeks to build capacity in academic and research mentors. This curriculum was originally developed at the University of Wisconsin-Madison for use with doctoral students in scientific fields [3], and later adapted and expanded with funding from the National Science Foundation (NSF), the National Institutes of Health (NIH), and other agencies. The 2017 Entering Mentoring Facilitator Training was co-sponsored by the National Research Mentors Network (NRMN), which was developed to support individuals" "advancement at every career stage of research in the biomedical sciences," and the Big Ten Academic Alliance [4]. Building on 15 years of work, colleagues at the University of Wisconsin have demonstrated that high-quality training can improve mentors' skills and increase positive experiences and research skills for mentees [5][7]. The Center for the Improvement of Mentored Experiences in Research (CIMER) at the University of Wisconsin-Madison was founded in 2017 to sustain and expand this work and to provide "resources for organizations and institutions to improve research mentoring relationships" [8]. CIMER offers training for both mentees and mentors in different disciplines and a variety of career stages (undergraduate, graduate students, postdoctoral scholars, junior and senior faculty).

"Entering Mentoring" [3] is one of the central training programs offered by CIMER, and is a modular curriculum with flexible materials covering topics such as:

- Aligning Expectations

- Maintaining Effective Communications

- Promoting Professional Development

- Articulating Mentoring Philosophy and Plan
- Assessing Understanding

- Fostering Independence

- Addressing Equity and Inclusion

- Cultivating Ethical Behavior 
Similar training is available through CIMER for research mentees, called "Entering Research" [9]. As CIMER's mission is to build capacity for inclusive research mentoring nationwide, the organization also delivers Entering Mentoring and Entering Research Facilitator Training to build a national network of individuals who want to facilitate training activities on their own campuses. The curriculum materials themselves are freely available to registered users of the CIMER webportal (www.cimerproject.org); registration is required so that CIMER can keep track of how often various materials are accessed. The CIMER website provides pre-made curricula for download, and also allows facilitators to create customized trainings by selecting activities and materials from the database based on the type of training (mentor, mentee, "mentoring up", etc.), the audience (students, scholars, faculty, etc.) and the competency (from the list above). These selections can be downloaded individually or the website can compile them into a customized curriculum manual for the user.

After being trained as a facilitator for "Entering Mentoring," the DEF began to offer this training to Engineering graduate students at Michigan State University. With permission from CIMER, the DEF also made the "Entering Mentoring" curriculum available as part of the Engineering Futures program of Tau Beta Pi. Collegiate chapters of TBP are typically focused on undergraduate students, although graduate students are also eligible for membership. Adding the "Entering Mentoring" training to the EF catalog created a new opportunity to serve graduate students in engineering with materials uniquely relevant to their experiences in graduate research and training. Yet the overall reach of the "Entering Mentoring" module within Tau Beta Pi has remained small, given the EF program's historical focus on undergraduate training. A new approach was needed to expand the impact of these materials to a broader audience.

\section{Developing a Module on Equity, Inclusion and Ethics for Engineers}

While the "Entering Mentoring" and "Entering Research" curricula are high-quality and have been demonstrated to positively impact the behaviors and experiences of mentors and mentees, they were initially designed for a very specific audience: researchers in the biological sciences. Over time, these curricula were adapted to audiences from other areas of STEM (science, technology, engineering, math) and for multidisciplinary research groups. Yet the focus remains on mentorship in research contexts. The primary audience for the Tau Beta Pi EF program is undergraduate engineering students, who are not typically involved in research mentoring relationships. Thus, the decision was made to adapt the CIMER materials to serve a specific need within the audience of undergraduate engineering students: raising awareness about issues of equity, inclusion and ethics in engineering.

The bulk of the information and exercises for this Equity, Inclusion \& Ethics (EIE) training were adapted from the "Entering Research" manual [9]. Additional sources include "Entering Mentoring" [3]; CIMER (cimerproject.org); NRMN (nrmnet.org); the National Society of Professional Engineers (nspe.org); and the contributions of facilitators from the Engineering Futures Program of Tau Beta Pi. The training was designed to foster small and large group discussions, with a focus on interactive activities rather than presentations or slides (in fact, flip charts are the recommended instructional medium). 
The training is divided into three sections, beginning with an Introduction. As outlined in the facilitator's manual, "Establishing group dynamics and laying the ground rules are perhaps two of the most important steps to a successful training. Once established, these parameters help ensure participants engage in shared learning of ways to become more conscious of equity, inclusion and ethics issues as they relate to the practice of engineering." The learning objectives and core activities for the Introduction section are described in Table 1.

Table 1: Learning Objectives and Core Activities for Introduction Section

\begin{tabular}{|c|c|}
\hline Learning Objective & Core Activities \\
\hline $\begin{array}{l}\text { 1. Learn about other members in the group and } \\
\text { begin building a learning community }\end{array}$ & 1. Introductions \\
\hline $\begin{array}{l}\text { 2. Reflect on group dynamics and ways to } \\
\text { make the group functional }\end{array}$ & $\begin{array}{ll}\text { 2. Examining constructive and } \\
\text { destructive group behaviors }\end{array}$ \\
\hline 3. Establish ground rules for participation & 3. Generate ground rules \\
\hline
\end{tabular}

The introductory activities are particularly important because they help participants identify deeper connections (beyond major or home department) and begin building trust and a learning community. The list of suggested introduction activities that is provided as part of the facilitator manual for the EIE training is included in Appendix A. The examination of constructive and destructive group behaviors asks participants to consider their own preferred styles of interactions in groups (e.g., speaking vs. listening, engaging vs. withdrawing), based on a list of constructive and destructive behaviors provided in a handout. Each participant is asked to pick just one item from each set of options, even if it's not a perfect fit or they feel that they identify with several items, and share their selections in their small group. After the small group discussion, each person is asked to note their choices on a flip chart tally sheet, which allows the facilitator to lead a discussion about the larger group's preferred styles. This exercise provides a vocabulary for participants to use when positive or negative behaviors arise during the training (e.g., "I can see some withdrawing in the room; what can we do to ensure that all voices are being heard?").

Creating ground rules is an essential part of the training, as talking about equity, inclusion and ethics can sometimes raise strong emotions and we want to create a safe and respectful environment for learning. The facilitator leads a brainstorming session with participants to elicit the ground rules that the group feels will be most appropriate to their training. Participants are asked to consider their expectations for themselves, as well as their expectations for others' participation. This is an opportunity to consider practical matters too, such as how does the group want to handle technology? (Some groups opt to ban cell phones except during breaks, other groups might choose to restrict them to specific uses, like translation programs if you have an international audience.) The facilitator may also ask the group to consider how they want to encourage constructive group behaviors, or discourage destructive behaviors. Once the ground rules have been established, they remain posted in the room throughout the training - and can be referred to and/or modified as needed throughout the session.

The second section of the EIE training focuses on raising awareness about equity and inclusion issues. The training manual provides a reminder to participants that "Diversity, in many dimensions, offers both challenges and opportunities to any relationship. Learning to identify, 
reflect upon, learn from, and engage with diverse perspectives is essential to fostering effective relationships and vibrant intellectual environments." The learning goals and associated activities for the Equity and Inclusion section of the EIE training are outlined in Table 2.

Table 2: Learning Objectives and Core Activities for Equity \& Inclusion Section

\begin{tabular}{|c|c|}
\hline Learning Objective & Core Activities \\
\hline $\begin{array}{l}\text { 1. Recognize the impact of conscious and } \\
\text { unconscious assumptions, preconceptions, } \\
\text { biases, and prejudices and acquire skills to } \\
\text { manage them }\end{array}$ & $\begin{array}{l}\text { 1. Reflect on Unconscious Assumptions } \\
\text { 2. Implications of Diversity Research }\end{array}$ \\
\hline $\begin{array}{l}\text { 2. Increase understanding of equity and } \\
\text { inclusion and their influence on engineering }\end{array}$ & 3. Case Study (Language Barriers) \\
\hline $\begin{array}{l}\text { 3. Identify concrete strategies for learning } \\
\text { about and addressing issues of equity and } \\
\text { inclusion }\end{array}$ & 4. Case Study (Is it OK to Ask?) \\
\hline
\end{tabular}

This part of the training begins with activities that elicit participants' assumptions about the workshop (e.g., that it would be interesting, boring, long, a waste of time, or expressions of uncertainty, eagerness, etc.) and about the "typical" person who pursues various careers (e.g., chef, teacher, doctor, engineer). These exercises are designed to raise participants' awareness of the fact that our brains have evolved to make assumptions as a way of managing the otherwiseoverwhelming amount of information that assaults our senses. Gravity and oxygen are essential to our everyday well-being (at least on Earth!), yet if our brains had to constantly reassure us that there is a floor beneath us and fresh oxygen to breathe, we would never have mental energy for anything else. So our brain has evolved shortcuts - assumptions - that allow us to rapidly understand and categorize the world around us according to what we already know. These assumptions are necessary, but sometimes they get in the way of fully understanding the world around us, particularly when we assume things about people based on our past experiences in similar situations. These implicit assumptions or unconscious biases [10] can interfere with our ability to truly understand and engage with the people around us. Becoming aware of these assumptions is the first step in understanding how and when to make use of them - and when to make a conscious effort to overcome or expand on our prior assumptions about the world.

After raising awareness about the existence of unconscious bias, the next activity asks participants to consider how unconscious (or conscious) biases might influence human behavior. A handout is provided that summarizes the results of 10 different research studies related to diversity, equity and inclusion. These studies explore topics ranging from physical, visible disabilities to assumptions about ability that might be unconsciously based on the gender or culture associated with a person's name. Small and large group discussions of these research results allow participants to consider the various ways that assumptions and unconscious biases can influence how people treat one another - and how this treatment can impact both personal and professional activities.

The remaining learning goals in this section are addressed through case study discussion activities, where participants are asked to read and respond to a scenario involving equity and inclusion issues in engineering contexts. The first case study included in this section is called 
"Language Barriers" and describes a situation where a visible minority (someone wearing a headscarf and speaking heavily-accented English) is giving a presentation when they are interrupted by a person in a more powerful role (e.g., their supervisor). The supervisor says (in a not-very-nice-way) they can't understand the presenter and asks them to speak more slowly, which flusters the presenter and causes them to speak even faster. Afterwards, the presenter comes to the person reading the case study and relates the story, questioning whether their visibly different religion and cultural background might have influenced how they were treated during the presentation.

The case study includes several discussion questions, and the facilitator leads the group through a discussion exercise that explores the issues of inclusion and equality that are raised by this case. There are typically no "right" or "wrong" answers when discussing a case study; instead, the goal is to give participants a common framework and context for thinking and talking about issues that can be difficult to address. The second case study in this section ("Is it OK to Ask?") explores a related theme: when, or if, it is okay to explicitly ask someone how they feel as a member of a minority group working or studying in a majority environment. This case is typically discussed first in small groups and then the facilitator engages in debriefing discussion with the larger group of participants. The CIMER website (cimerproject.org) provides many additional case studies related to Equity and Inclusion, and the facilitator's manual for the EIE module includes several of these additional options; this allows the facilitator to adjust or extend this portion of the training based on the audience and available time.

The third section of the EIE training focuses on ethics in the context of engineering research and practice. As noted in the participants' guide, "Engineers play an important role in both teaching and modeling ethical behavior. There are ethical issues centering on the underlying science how to conduct, report, and write scientific and engineering studies - as well as relationships between engineers and their colleagues, supervisors, and the public. Reflecting upon and discussing ethical behavior is an important part of becoming an effective engineer." Table 3 summarizes the learning goals and core activities for the Ethics portion of the EIE training.

Table 3: Learning Objectives and Core Activities for Ethics Section

\begin{tabular}{|c|c|}
\hline Learning Objective & Core Activities \\
\hline $\begin{array}{l}\text { 1. Become familiar with the code of ethics } \\
\text { developed by the Society of Professional } \\
\text { Engineers }\end{array}$ & $\begin{array}{l}\text { 1. Review NSPE Code of Ethics for } \\
\text { Engineers }\end{array}$ \\
\hline $\begin{array}{l}\text { 2. Articulate ethical issues in engineering } \\
\text { research and practice }\end{array}$ & $\begin{array}{l}\text { 2. Case Study (Tweaking the Data) } \\
\text { 3. Case Study (Plagiarism) }\end{array}$ \\
\hline $\begin{array}{l}\text { 2. Clarify their role in practicing ethical } \\
\text { behavior and educating others about ethics }\end{array}$ & 4. Case Study (A Big, Strong Guy) \\
\hline
\end{tabular}

As an initial activity, the participants are asked to review a handout that summarizes the "Code of Ethics for Engineers" published by the National Society of Professional Engineers (NSPE) [11]. (Note, if the training is being conducted for a group of participants from a specific engineering discipline, the facilitator is encouraged to substitute the code of ethics for that discipline or professional society in place of the more general NSPE code.) Participants are asked first to (physically) markup their copy of the handout, highlighting items that are 
particularly relevant to their own studies or work, or about which they have questions. Depending on the dynamics of the training, they facilitator may encourage small group conversations and/or facilitate a large group discussion of the Code of Ethics, including questions such as:

- How do these guidelines apply to your work (or to your major)?

- Who should be responsible for teaching this code of ethics to new engineers?

- How does this code of ethics apply to those engineers who cannot or choose not to become licensed as a Professional Engineer (PE)? (note: PE licensure is not available for all disciplines)

- What happens when engineers fail to follow these guidelines?

After discussing the applicable Code(s) of Ethics, participants shift back to case study discussions. "Tweaking the Data" asks participants to consider how the power differential between a supervisor/employee or mentor/mentee can impact the gathering and reporting of data. In this scenario, an inexperienced engineer is tasked with collecting data that ends up surprising and puzzling the project manager. The manager questions the results in some detail, trying to understand what happened, and the new engineer worries that they messed up somehow, and wonders if they should adjust future results to match what the manager is expecting to see. The discussion questions for this case include:

- How can you teach an engineer good ethical behavior?

- The entire scientific enterprise depends on trust (and the ability to repeat experiments), so what is the ethical responsibility of an engineer or scientist to keep a detailed notebook?

- How do new engineers learn ethical practices in their discipline? What is general and what is specific to the discipline?

- Are their special issues for learning ethical practices in multidisciplinary research? What are they?

- How can a mentor's reaction to the unexpected motivate or influence a mentee to make good or bad ethical choices? What is the issue or point of conflict?

In the case study titled "Plagarism," participants are asked to imagine what they would do as one member of a team of students working on a capstone project that has been assigned to develop a background report about the current state-of-the-art. The day of the deadline, another member sends their background section with what appears to be a large, plagiarized section of text (based on a quick internet search); the assignment is due today and the author can't be reached. This case study asks participants to consider what they would do, how they would meet the deadline, how responsibility (and potential consequences) should be divided among team members, and what might have been done differently to prevent this situation. This case study has a particular resonance for undergraduate engineering students, but is a familiar and challenging scenario for most participants with engineering backgrounds.

In the final case study, "A Big, Strong Guy," participants are asked to consider how gender stereotypes may influence engineering research and practice. This scenario outlines a field work setting involving manual labor, and a project manager who always asks for "a big, strong guy" to volunteer to help. When a female offers to assist, she is rejected as not capable. Participants are 
asked to consider what they might do or say in this particular situation, as well as how gender (or other) stereotypes might impact training and opportunities for members of minority groups. What happens if women aren't allowed to participate and gain experience in all aspects of this engineering process? How might gender stereotypes influence young women's decisions about what majors to pursue and what careers to consider? How can participants act to counter stereotypes and biases, and what are the ethical implications of this type of inclusion (or exclusion)?

At the end of the EIE training, participants are invited to complete a brief, online evaluation that asks about their perceptions of and satisfaction with the training and facilitator. This evaluation is designed to be accessible from a smartphone or tablet using either a QR code or a short URL, and participants are encouraged to spend a few minutes completing the evaluation before they leave the training. Results are reviewed by the DEF to assess both the training and the facilitators.

\section{The Facilitators' Guide}

Talking about equity, inclusion and ethical issues can be challenging, and the curriculum materials for facilitators includes guidance for maintaining a positive and productive learning environment. For example, facilitators are reminded to be aware of unconscious bias in their process of selecting volunteers to read case studies aloud. Participants who speak English as a second language may be less likely to volunteer - or may be less likely to be selected by facilitators who may be uncomfortable with a slower reading pace or an accented reading style. When a case study or a question involves a particular minority group, the temptation may be to ask a participant from that minority group to read the case aloud or to share their reactions with the group, even though no one person can "speak" for an entire population. Facilitators are cautioned against the tendency to "tokenize" participants based on visible (or invisible) differences, and encouraged to be inclusive of everyone - while also recognizing that individuals have different tolerances for sharing in small and large group settings, and sometimes it's okay to be more or less vocal within a group.

The curriculum guide also reminds facilitators that they are not expected to be an expert on these topics, but instead their goal is to help participants consider equity, inclusion and ethics issues from a broader perspective. Participants often have widely varying views of the impact of race, class, ethnicity, gender, disability, age, sexual orientation, and background on engineering research and practice, and the facilitator's guide includes examples of some common comments that might be expressed during these sessions, such as:

- "Race, gender, class, ethnicity, sexual orientation, personal values, and other aspects of diversity have nothing to do with a research experience because the experience should focus on research and not on personal characteristics. It would not be fair to treat one lab member differently than another. The approach to the research must be objective and influenced as little as possible by the individual doing the research."

- "Race, gender, class, ethnicity, sexual orientation, personal values, and other aspects of diversity have everything to do with a research experience and permeate every aspect of 
the experience, impacting perceptions, confidence, and motivation. Ignoring the impact of diversity sends a message that those aspects of a person have no role in one's work, which may turn students off to science. The level of impact will vary across the relationship. At times it may be invisible. At other times, it may be the most important factor."

- "Individuals want to be assessed for their ability, independent of race, gender, and other aspects of diversity. The trick is deciding how to balance acknowledging someone's background and taking it into considerations when deciding how to work with that person, but not letting a person's background bias your interaction with them."

- "Regular conversations with all mentees to check on how they are doing and whether they are happy in their overall environment are important. This builds relationships that allow mentees to be comfortable sharing concerns; it also allows mentors to notice if there are issues surrounding race or other diverse personal characteristics that need to be addressed, or identify opportunities for growth."

Of course, this is not an exhaustive list of perspectives that might be expressed during the EIE training. However, they are provided in the facilitator's guide as a way of helping facilitator prepare to handle the range of views that may emerge.

\section{Facilitator Training}

In January 2018, a group of experienced EF facilitators from Tau Beta Pi gathered for a "train the trainers" (TTT) session to learn to facilitate the new EIE module. This training was facilitated by an experienced trainer from NRMN/CIMER and included a full day of activities separated into several parts:

1. Introduction and Welcome

2. Part 1: Experiencing the Training

a. Group Dynamics (Constructive and Destructive Group Behaviors)

b. Aligning Expectations

i. Case Studies

c. Cultivating Ethical Behavior

i. Case Studies

d. Addressing Equity and Inclusion

i. Diversity Study Results

ii. Case Studies

3. Part 2: Facilitating the Training

a. Facilitation Techniques \& Overview of Practice Facilitation

b. Practice Facilitation (small groups)

c. Practice Facilitation Debrief (large group)

4. Part 3: Planning your Implementation

a. Implementation Challenges and Strategies

b. Implementation Resources

5. Wrap up, evaluations, adjournment 
This was a highly interactive training program, including opportunities to both experience the curriculum as a participant and to practice facilitating case studies and other activities central to this type of interactive training experience. Within each part of the training, participants had the opportunity to engage with the new curriculum materials (as participants) and to reflect on the processes used to facilitate and coordinate these activities. Participants were also asked to reflect on their own experiences, thoughts and feelings about the training they experienced - and about their questions, concerns, or anticipation of facilitating this material on their own.

Twenty three (23) engineers, almost all experienced EF facilitators, participated in the training. A post-training evaluation survey was conducted by CIMER, and had 20 respondents. (Note: the CIMER evaluation platform is designed primarily to gather data from participants in mentor/mentee training, from which the EIE curriculum is adapted. Thus, many of the questions asked of participants reference mentor/mentee training, which our respondents interpreted to mean this EIE facilitator training.) All participants had college degrees in engineering, and 4 identified as affiliated with academic institutions (faculty, staff, or graduate student); another 11 responded that they worked (or were retired from) engineering careers in government or industry. 53\% identified as male, with $40 \%$ identifying as female and the remainder preferring not to respond. $93 \%$ of the respondents identified as white/Caucasian, and 1 person identified as Hispanic/Latinx.

Participants were asked to evaluate the value of various aspects of the training using Likert scales from 1 (Not at All Valuable) to 5 (Extremely Valuable). As summarized in Table 4, participants generally found the workshop components to be very valuable in learning to facilitate the EIE curriculum. Participants were also asked about their level of confidence in their ability to facilitate the EIE curriculum before and after the training, using Likert scales from 1 (Not at All Skilled) to 7 (Extremely Skilled). Overall, participants' confidence increased substantially after the training, as described by Table 5 .

Table 4: How valuable was each of the following aspects of the training?

\begin{tabular}{|l|c|c|c|c|c|c|c|}
\hline \multicolumn{1}{|c|}{ Question } & $\begin{array}{c}\text { Not at All } \\
\text { Valuable } \\
\text { (1) }\end{array}$ & $\begin{array}{c}\text { Somewhat } \\
\text { Valuable } \\
\text { (2) }\end{array}$ & $\begin{array}{c}\text { Valuable } \\
\text { (3) }\end{array}$ & $\begin{array}{c}\text { Very } \\
\text { Valuable } \\
\text { (4) }\end{array}$ & $\begin{array}{c}\text { Extremely } \\
\text { Valuable } \\
\text { (5) }\end{array}$ & $\mathbf{N}$ & Mean \\
\hline $\begin{array}{l}\text { Modeled Research Mentor } \\
\text { Training Introductory and } \\
\text { Communication Session }\end{array}$ & 0 & 1 & 1 & 6 & 8 & 16 & 4.31 \\
\hline $\begin{array}{l}\text { History of the Curricula } \\
\text { Overview }\end{array}$ & 0 & 1 & 6 & 5 & 4 & 16 & 3.75 \\
\hline $\begin{array}{l}\text { How to Use the Curricula } \\
\text { Overview }\end{array}$ & 0 & 0 & 4 & 4 & 8 & 16 & 4.25 \\
\hline Facilitation Basics & 0 & 1 & 3 & 4 & 8 & 16 & 4.19 \\
\hline $\begin{array}{l}\text { Practice Facilitation Sessions } \\
\text { and Debrief }\end{array}$ & 0 & 0 & 5 & 2 & 8 & 15 & 4.20 \\
\hline Data/Evidence for Recruitment & 0 & 2 & 4 & 5 & 1 & 12 & 3.42 \\
\hline Website Overview & 0 & 1 & 4 & 5 & 4 & 14 & 3.86 \\
\hline $\begin{array}{l}\text { Drafting a Training } \\
\text { Implementation Plan }\end{array}$ & 0 & 0 & 3 & 5 & 4 & 12 & 4.08 \\
\hline $\begin{array}{l}\text { Evaluation Measures of } \\
\text { Research Mentor Training }\end{array}$ & 0 & 0 & 1 & 7 & 4 & 12 & 4.25 \\
\hline
\end{tabular}


Table 5: Confidence in Abilities Before and After Attending the Training

\begin{tabular}{|c|c|c|c|c|c|c|c|c|c|c|}
\hline \multicolumn{11}{|c|}{ Not at All Skilled............................Extremely Skilled } \\
\hline Question & & 1 & 2 & 3 & 4 & 5 & 6 & 7 & $\mathbf{N}$ & Mean \\
\hline \multirow{2}{*}{$\begin{array}{l}\text { To utilize the available research mentor training } \\
\text { curricula and supporting resources }\end{array}$} & BEFORE & 4 & 3 & 4 & 2 & 1 & 1 & 0 & 15 & 2.73 \\
\hline & AFTER & 0 & 0 & 1 & 0 & 5 & 6 & 3 & 15 & 5.67 \\
\hline \multirow{2}{*}{$\begin{array}{l}\text { To describe evidence to support the effectiveness of } \\
\text { research mentor training }\end{array}$} & BEFORE & 8 & 3 & 2 & 1 & 1 & 0 & 0 & 15 & 1.93 \\
\hline & AFTER & 0 & 1 & 2 & 3 & 3 & 4 & 2 & 15 & 4.87 \\
\hline \multirow{2}{*}{$\begin{array}{l}\text { To facilitate research mentor training using the process- } \\
\text { based approach }\end{array}$} & BEFORE & 5 & 5 & 1 & 1 & 2 & 0 & 1 & 15 & 2.60 \\
\hline & AFTER & 0 & 1 & 0 & 1 & 3 & 4 & 6 & 15 & 5.80 \\
\hline \multirow[t]{2}{*}{ To recruit mentors to participate in training } & BEFORE & 5 & 5 & 1 & 0 & 2 & 1 & 1 & 15 & 2.73 \\
\hline & AFTER & 0 & 2 & 1 & 3 & 2 & 6 & 1 & 15 & 4.80 \\
\hline \multirow{2}{*}{$\begin{array}{l}\text { To facilitate research mentor training using the process- } \\
\text { based approach }\end{array}$} & BEFORE & 5 & 4 & 1 & 2 & 0 & 0 & 1 & 13 & 2.38 \\
\hline & AFTER & 0 & 1 & 0 & 2 & 4 & 4 & 2 & 13 & 5.23 \\
\hline \multirow{2}{*}{$\begin{array}{l}\text { To use metrics and tools to assess the effectiveness and } \\
\text { impact of research mentor training }\end{array}$} & BEFORE & 5 & 4 & 3 & 0 & 1 & 0 & 0 & 13 & 2.08 \\
\hline & AFTER & 1 & 0 & 1 & 2 & 7 & 2 & 0 & 13 & 4.54 \\
\hline \multirow[t]{2}{*}{ To understand the implementation process } & BEFORE & 5 & 7 & 0 & 2 & 0 & 1 & 0 & 15 & 2.20 \\
\hline & AFTER & 0 & 0 & 1 & 5 & 1 & 6 & 2 & 15 & 5.20 \\
\hline \multirow[t]{2}{*}{ Composite } & BEFORE & & & & & & & & & 2.38 \\
\hline & AFTER & & & & & & & & & 5.16 \\
\hline
\end{tabular}

\section{Results from the First Year}

During the 2018-19 academic year, the Equity, Inclusion and Ethics (EIE) session was formally added to the Engineering Futures curriculum available by request of student chapters of Tau Beta Pi. Not surprisingly, the new materials were quite popular and became the second-mostrequested session in its debut year (Team Chartering, which was slightly more popular, is a shorter module and often selected by hosts with limited training time). Table 6 summarizes the distribution of EF sessions during 2018-19 by topic and delivery format (in that year, we also piloted a range of new training materials in both online and in-person sessions).

EF participants are invited to complete a brief, online evaluation at the conclusion of each training. This evaluation asks just 6 questions and focuses primarily on participants' interests in and satisfaction with the training. Table 7 summarizes the results from these evaluation surveys completed by participants between Spring 2017 and Spring 2019, and show that over $80 \%$ of respondents felt that the EIE training was helpful and/or a good use of their time. It is worth noting that we opted not to conduct a more detailed evaluation of the impact of the EIE training on participants for two reasons: first, NRMN and CIMER have collected a wealth of data to indicate that the baseline curriculum for EIE is effective and can positively influence the behavior of mentors and mentees [5], [7], [12]-[14]. Second, there is a significant practical challenge in asking EF participants, who are largely undergraduate engineering students, to complete a lengthy evaluation form. Over the decades of the EF program, we have used various paper and online evaluations to gather information about the quality and impact of these trainings, which provides an excellent baseline of comparison for future trainings. We have found that the 6 questions in the current online evaluation are both effective at capturing participants' levels of interest and engagement in the training, and are easy enough to complete at the end of the training using a smartphone that we have a strong response rate. 
Table 6: 2018-19 Session Data by Module and Delivery Format

\begin{tabular}{|c|c|c|c|c|}
\hline Module & \# Sessions & $\begin{array}{l}\% \text { of Total } \\
\text { Sessions }\end{array}$ & \# Participants & $\begin{array}{c}\% \text { of Total } \\
\text { Participants }\end{array}$ \\
\hline Team Chartering & 29 & $19 \%$ & 500 & $15 \%$ \\
\hline Equity, Inclusion \& Ethics & 20 & $13 \%$ & 326 & $10 \%$ \\
\hline Group Process & 16 & $11 \%$ & 304 & $9 \%$ \\
\hline Analytical Problem Solving & 18 & $12 \%$ & 301 & $9 \%$ \\
\hline People Skills & 18 & $12 \%$ & 277 & $8 \%$ \\
\hline Mentoring & 10 & $7 \%$ & 262 & $8 \%$ \\
\hline Effective Presentation Skills & 13 & $9 \%$ & 171 & $5 \%$ \\
\hline Pilot Modules (online) & 8 & $5 \%$ & 792 & $23 \%$ \\
\hline Pilot Modules (in person) & 20 & $13 \%$ & 473 & $14 \%$ \\
\hline
\end{tabular}

Table 7: Participant Evaluations, Spring 2017 through Spring 2019

\begin{tabular}{|c|c|c|c|c|c|c|}
\hline & $\begin{array}{l}\text { Analytical } \\
\text { Problem } \\
\text { Solving }\end{array}$ & $\begin{array}{l}\text { Effective } \\
\text { Presentation } \\
\text { Skills }\end{array}$ & $\begin{array}{l}\text { Equity and } \\
\text { Inclusion }\end{array}$ & $\begin{array}{l}\text { Group } \\
\text { Process }\end{array}$ & $\begin{array}{l}\text { People } \\
\text { Skills }\end{array}$ & $\begin{array}{c}\text { Team } \\
\text { Chartering }\end{array}$ \\
\hline \multirow[t]{2}{*}{ Total Respondents } & 962 & 571 & 336 & 723 & 1065 & 1038 \\
\hline & \multicolumn{6}{|c|}{ Percent answering "Strongly Agree" or "Agree" } \\
\hline $\begin{array}{l}\text { I wanted to participate in } \\
\text { this session. }\end{array}$ & $78 \%$ & $74 \%$ & $82 \%$ & $76 \%$ & $74 \%$ & $81 \%$ \\
\hline $\begin{array}{l}\text { I found the session } \\
\text { material interesting or } \\
\text { helpful. }\end{array}$ & $81 \%$ & $80 \%$ & $86 \%$ & $79 \%$ & $77 \%$ & $87 \%$ \\
\hline $\begin{array}{l}\text { The facilitator explained } \\
\text { the material clearly. }\end{array}$ & $85 \%$ & $82 \%$ & $87 \%$ & $81 \%$ & $83 \%$ & $90 \%$ \\
\hline $\begin{array}{l}\text { The facilitator was } \\
\text { knowledgeable. }\end{array}$ & $86 \%$ & $82 \%$ & $88 \%$ & $83 \%$ & $83 \%$ & $90 \%$ \\
\hline $\begin{array}{l}\text { The facilitator was } \\
\text { enthusiastic. }\end{array}$ & $85 \%$ & $82 \%$ & $88 \%$ & $82 \%$ & $83 \%$ & $89 \%$ \\
\hline $\begin{array}{l}\text { I would recommend } \\
\text { Engineering Futures to } \\
\text { my friends. }\end{array}$ & $79 \%$ & $79 \%$ & $84 \%$ & $77 \%$ & $75 \%$ & $84 \%$ \\
\hline
\end{tabular}

\section{Discussion and Future Work}

The EIE module has proven to be an effective and popular introduction to equity, inclusion and ethics issues for undergraduate students, and participation helps to raise awareness of these challenges in engineering contexts. However, EIE is only an introduction and often leaves participants with many unanswered questions about how to recognize and respond to ethical challenges, or how to foster inclusion in the classroom or workplace. While facilitators can recommend additional reading or resources, and we encourage students to seek out additional training, some participants find the open-ended nature of discussions in EIE to be discomforting. This is a natural (and perhaps positive) outcome of a module dedicated to challenging topics like ethics and diversity, but also points to the need for additional training and support for engineering students to help them develop into ethical and inclusive professionals. 
Developing the EIE module to expand the EF program offerings is just the beginning of a longerterm (3-5 year) plan to completely replace the existing EF materials with new, open-source curriculum. We want to create a flexible suite of materials that can be adapted to different audiences, including students, alumni and non-members (particularly those who may be eligible for membership at some point). To this end, Tau Beta Pi collaborated on a proposal submitted to the National Science Foundation to develop professional skills training for cyberinfrastructure professionals, and then adapt these materials for a broader audience of engineers. This project was funded (NSF Award \#1730137) and is currently in the final year of the three-year project that includes: developing the curriculum; testing and revising the materials; and "training the trainers" so that the curriculum can be deployed nationally. This project is developing a modularized, flexible, open-source curriculum that emphasizes interactive exercises (role playing / rehearsal, case studies, discussion). More than 400 participants and nearly 50 facilitators were trained during the first two years of the project [15]-[17] and Tau Beta Pi will assist in administering the curriculum and training after the end of the grant, allowing the project to continue to provide high-quality, low-cost training to STEM students and professionals.

Expanding the EF program also offers opportunities to collaborate with and contribute to other efforts to expand access to professional skills training in STEM. For instance, in the last two years the EF program has offered free professional skills training to scientists and engineers in collaboration with the American Society for Engineering Education; the National Postdoctoral Association; the Conference for Undergraduate Women in Physics; and the Campus Research Computing Consortium. The EF program serves about 4,000 participants annually, and there is substantial capacity for growth as we expand the EF program catalog to include more flexible trainings delivered both in-person and online.

\section{Acknowledgements}

A special thanks to Dr. Christine Pfund, Ph.D., a Principal Investigators of NRMN (NIH \#U54 MD0009479-01) and Director of the Center for the Improvement of Mentored Experiences in Research (CIMER) at the University of Wisconsin Center for Education Research for her advice and counsel on the project.

\section{References}

[1] K. Patterson, J. Grenny, R. McMillan, and A. Switzler, Crucial Conversations: Tools for Talking When Stakes Are High, Second Edition. McGraww Hill, 2012.

[2] J. R. Luchini, "What Mother Never Told You About Engineering Futures," The Bent of Tau Beta Pi, no. Winter, pp. 14-18, 2014.

[3] J. Handelsman, C. Pfund, S. Miller Lauffer, C. Maidl Pribbenow, and others, "Entering mentoring: a seminar to train a new generation of scientists," Ethics in Science and Engineering National Clearinghouse, p. 164, 2005.

[4] "About the National Research Mentoring Network (NRMN) - NRMNet." https://nrmnet.net/about-nrmn-2/ (accessed Feb. 17, 2019).

[5] J. Rogers, C. A. Sorkness, K. Spencer, and C. Pfund, "Increasing research mentor training among biomedical researchers at Clinical and Translational Science Award hubs: The impact of the facilitator training initiative," $J$ Clin Transl Sci, vol. 2, no. 3, pp. 118-123, Jun. 2018, doi: 10.1017/cts.2018.33. 
[6] C. Pfund, A. Byars-Winston, J. Branchaw, S. Hurtado, and K. Eagan, "Defining Attributes and Metrics of Effective Research Mentoring Relationships,” AIDS Behav, vol. 20, no. 2, pp. 238-248, Sep. 2016, doi: 10.1007/s10461-016-1384-z.

[7] A. Byars-Winston et al., "Pilot Study of an Intervention to Increase Cultural Awareness in Research Mentoring: Implications for Diversifying the Scientific Workforce," J Clin Transl Sci, vol. 2, no. 2, pp. 86-94, Apr. 2018, doi: $10.1017 /$ cts.2018.25.

[8] “CIMER." https://cimerproject.org/\#/services/training (accessed Feb. 17, 2019).

[9] "Macmillan Higher Education: Entering Research: A Facilitator's Manual by Janet L. Branchaw; Christine Pfund; Raelyn Rediske."

http://www.macmillanhighered.com/Catalog/product/enteringresearchafacilitatorsmanual-branchaw (accessed Oct. 16, 2015).

[10] "Who, Me? Biased?," PBS LearningMedia. https://wkar.pbslearningmedia.org/resource/pov-biasedlpclips/who-me-biased/ (accessed Feb. 02, 2020).

[11] "Code of Ethics | National Society of Professional Engineers." https://www.nspe.org/resources/ethics/codeethics (accessed Feb. 02, 2020).

[12] "Building a Sustainable National Infrastructure to Expand Research Mentor Training." https://www.ncbi.nlm.nih.gov/pmc/articles/PMC6234808/ (accessed Feb. 02, 2020).

[13] C. A. Sorkness et al., "A new approach to mentoring for research careers: the National Research Mentoring Network," BMC Proc, vol. 11, no. 12, p. 22, Dec. 2017, doi: 10.1186/s12919-017-0083-8.

[14] L. R. Guerrero et al., "Using collaborative approaches with a multi-method, multi-site, multi-target intervention: evaluating the National Research Mentoring Network," BMC Proceedings, vol. 11, no. 12, p. 14, Dec. 2017, doi: 10.1186/s12919-017-0085-6.

[15] A. Briliyanti, J. Rojewski, T. V. Nguyen, K. Luchini-Colbry, and D. Colbry, "The CyberAmbassador Training Program," in Proceedings of PEARC 2019, Chicago, Illinois, 2019.

[16] K. Luchini-Colbry, C. McComb, J. Rojewski, A. Briliyanti, and D. J.-L. Colbry, "Engineering Futures: Updating a Successful Professional Development Program to Address New Challenges," presented at the 2019 ASEE Annual Conference \& Exposition, Jun. 2019, Accessed: Jan. 24, 2020. [Online]. Available: https://peer.asee.org/engineering-futures-updating-a-successful-professional-development-program-to-addressnew-challenges.

[17] K. Luchini-Colbry, D. J.-L. Colbry, J. Rojewski, and A. Briliyanti, "Partners in Professional Development: Initial Results from a Collaboration Between Universities, Training Programs, and Professional Societies," presented at the 2019 ASEE Annual Conference \& Exposition, Jun. 2019, Accessed: Jan. 24, 2020. [Online]. Available: https://peer.asee.org/partners-in-professional-development-initial-results-from-a-collaborationbetween-universities-training-programs-and-professional-societies. 


\section{Appendix A: Suggested Introductory Exercises}

1. Common Ground. Ask participants to stand in a circle facing each other. Each person should introduce him/herself (name, major or institution) and then share one fact about themselves that they think might also be true of other people in the room. For example, "I like kayaking" or "I watch a lot of Netflix." If the statement applies to you, then you step forward into the circle briefly. Then everyone steps back and the next person introduces $\mathrm{him} /$ herself. Each person should pick a different "interesting" fact to share (no repeats). The goal of this exercise is to begin developing a sense of community among the participants. (Note: if you are facilitating with a mixed group of participants, such as faculty and students together, you may want to focus on names and interesting characteristics only, rather than including titles or roles, which can unintentionally emphasize differences in status.)

2. The Name Game. Have participants stand in a circle and take turns introducing themselves. They should be asked to give their name and share how they got their name. For instance, "I'm Alberta and my mom promised my dad I'd be named after him - even if I wasn't a boy!" (Note: this exercise can be particularly interesting in a diverse group, as there are often cultural influences to naming decisions.)

3. Who are You? Have participants add fun information about themselves to the four corners of their nametags/table tents. Choose four specific items, to avoid confusion; examples include: hometown, favorite food, favorite tv show, hobby, favorite kind of music, number of people in their family (the way that each person defines "family" can be very interesting!). Have each person introduce him/herself and share this information.

4. Interviews. Have participants pair up with someone they do not know, and interview them briefly. Have each person introduce his/her partner to the group.

5. Two Truths and a Lie. Have participants write down two true statements and one lie; each of the statements should tell you something about the participant. Have each person introduce $\mathrm{him} /$ herself and read the statements to the group, and have the group try to guess which is false.

6. Memorable Moments. Ask each participant to share something memorable about their mentoring experience (as a mentor or mentee) and their motivation for participating in this mentor training program.

7. Letter Names. Each person says their name and shares characteristics that start with the first letter of their name.

8. The M\&M Game. Pass around a dish of M\&M candies and tell participants to take as many as they would like. Ask them to introduce themselves by sharing as many characteristics about themselves as is equal to the number of M\&Ms they took from the dish. 